\title{
The role of resveratrol in hepatotoxicity caused by methotrexate
}

\author{
Meltem Özgöçmen ${ }^{1}$, Şükriye Yeşilot ${ }^{2}$ \\ ${ }^{1}$ Department of Histology and Embryology, Faculty of Medicine, Süleyman Demirel University, Isparta/TURKEY \\ ${ }^{2}$ Department of Nursing, Bucak School of Health, Mehmet Akif Ersoy University, Burdur/TURKEY
}

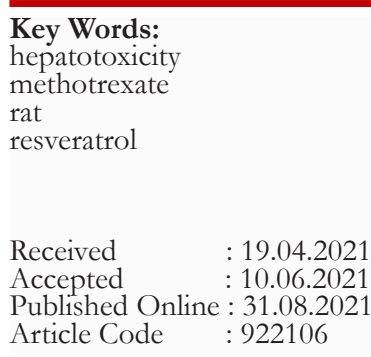

Correspondence:

M. ÖZGÖCMEN

(meltemozgocmen@sdu.edu.tr)

ORCID

M. ÖZGÖCMEN : 0000-0003-3190-4486

S. YESSILOT : 0000-0003-3354-8489

\begin{abstract}
Methotrexate is an immunosuppressive and antineoplastic drug that may induce hepatotoxicity. Resveratrol is a compound that has a protective effect thanks to its antioxidant role. In present study was aimed to investigate posibble protective effects of resveratrol in methotrexate induced hepatotoxicity. Eighteen Wistar Albino rats were equally divided into three groups: Control, Methotrexate, Methotrexate + Resveratrol. After a single dose of methotrexate (15 mg/kg, i.p.), resveratrol (10 mg/kg, orally) was applied for 7 days. Fallowing 7 days, rats were sacrificed. Histopathological (H-E staining), immunohistochemical (Tumor Necrosis Factor Alpha, inducible Nitric Oxide Synthases, Nuclear Factor Kappa) and biochemical (Total Oxidant Status, Total antioxidants Status and Oxidative Stress Index) analyses were assayed in liver tissue samples. Additionally, Aspartate Aminotransferase, Alanine Aminotransferase, Gamma Glutamyl Transferase and Total Biluribin activities were assayed in serum samples for biochemical analyses. Normal liver tissues were observed in control groups. Histopatholocigal changes, high staining of Tumor Necrosis Factor Alpha, inducible Nitric Oxide Synthases, Nuclear Factor Kappa, increasing levels of tissue Total Oxidant Status, Oxidative Stress Index and decreasing levels of tissue Total antioxidants Status were observed in methotrexate groups. Moreover, Aspartate Aminotransferase, Alanine Aminotransferase, Gamma Glutamyl Transferase and Total Biluribin levels increased in methotrexate groups too $(\mathrm{p}<0.05)$. However, these findings were lower in the Methotrexate + Resveratrol groups $(p<0.05)$. In this study were observed that oxidant levels could increase after methotrexate applied in the liver, whereas resveratrol alleviated effects of hepatotoxicity by histopathological, immunohistochemical and biochemical analyses.
\end{abstract}

\section{INTRODUCTION}

Methotrexate (Mtx), a folic acid antagonist, is one of antiinflammatory, immunosuppressive, antiproliferative, antioxidant and cytotoxic agent that effectively reduces cellular growth and is widely used in the treatment of several diseases, including: ectopic pregnancy, rheumatoid arthritis, leukemia, systemic lupuserythematosus, psoriasis neoplastic diseases (14).

Methotrexate is typically well tolerated by patients and still the first choice as the cost effective and well-experienced treatment option (5). It has many application fields as a therapeutic agent at low doses in autoimmune diseases and at high doses in many malignancies. Despite of wide usage, Mtx has a range of side effects such as hepatotoxicity - nephrotoxicity (4, 6-9). Therefore, it has been advised to prevent Mtx induced hepatotoxicity, it is using concomitant with antioxidants (10).

The exact molecular mechanisms underlying Mtx hepatotoxicity are not clearly understood. Recent studies have indicated that Mtx induced hepatic injury may be due to increasing levels of reactive oxygen species (ROS), hydroxyl radicals and hydrogen peroxide as a result of oxidative injury of the DNA and triggers lipid peroxidation along with decreased levels of antioxidant defense molecules $(8,11-14)$.

Resveratrol (Rsv) (3,4',5-trihydroxystilbene) is well-known as an important phytoalexin and bioactive compounds, found in a large variety of plants including, plums, grapes blueberries and peanuts $(1,15)$. Rsv has been studied for a several decades in different therapeutic research areas and epidemiological studies have observed the relationship between consumption of Rsv and healthy $(16,17)$. Laboratory animals are used in many experimental studies(18-21). In numerous experimental studies reported that resveratrol possesses many bioactivities and has beneficial for healthy like antioxidant, anti-inflammatory, improving diseases and also has a hepatoprotective effect $(22,23)$.

Although many studies of the metabolism of Rsv in both humans and animals, it is still unclear. In addition, the protective effect of bioactive compounds has been attributed to their antioxidant roles. In liver studies, it is known that the proliferation of stellate cells, which has important role in liver damage, is enhanced via oxidative stress. For this reason, bioactive compounds, which can reduce role of this cells, may prevent the hepatic damage $(23,24)$.

In prensent study, a rat model was planed to investigate protective effects of Rsv on liver damage by acute Mtx-induced. For this aim, histopathological - immünohistochemical changes and levels of tissue antioxidants - oxidants were measured in Mtx by resveratrol treatment. We believe that this study will useful for other studies with Mtx + Rsv especially TNF- $\alpha-$ 
iNOS - NF-kB staining. In addition, we are contining to work with other antibodies to understand the molecular pathway of Rsv more clearly.

\section{MATERIAL and METHODS}

\section{Experimental Desing}

Eighteen female Wistar Albino rats weighting 250 - $300 \mathrm{~g}$ were used and were kept in cages under standard humidity, $12 \mathrm{~h}$ light $/ 12 \mathrm{~h}$ darkness and $22 \pm 2{ }^{\circ} \mathrm{C}$ conditions during the 7 days. The animals were provided unlimited access to water and food. Study was approved by the Local Ethical Committee of Experimental Animal Ethics of Mehmet akif Ersoy University (MAKÜ, Ethical number: 17.03.2021-87/742) and was performed entirely according to ethical rules.

\section{Experimental Protocol}

Rats were randomly divided into three groups with 6 rats in each groups.

Control group: $0.9 \%$ saline $(1 \mathrm{~mL} / \mathrm{kg}$ - single dose, i.p)

Mtx group: $15 \mathrm{mg} / \mathrm{kg}$ Mtx (single dose, i.p)

Mtx + Rsv group: $15 \mathrm{mg} / \mathrm{kg}$ Mtx (single dose, i.p) + $20 \mathrm{mg} /$ $\mathrm{kg}$ Rsv, (oral gavage, 7 days)

Group I served as the control group and treated with a single intraperitoneal injection (IP) of $0.9 \%$ saline $(1 \mathrm{~mL} / \mathrm{kg})$ on the day 1 st. Group II (Mtx) was treated with a single IP of methotrexate (Koçak Farma, Tekirdag, Turkey) (15mg/ $\mathrm{kg}$ ) on 1st day of the experiment(25). Group III (Mtx + Rsv) was treated with Resveratrol (Solgar, ABD) at $20 \mathrm{mg} / \mathrm{kg}$ daily (suspended in distilled water)(26) $1 \mathrm{~h}$ before Mtx admistration, orally for 7 consecutive days and treated with methotrexate (15 $\mathrm{mg} / \mathrm{kg}, 1$ th day, IP).

\section{Sample collection and preparation}

Fallowing experimental procedure, anaesthesia was apllied by xylazine $(10 \mathrm{mg} / \mathrm{kg})$ and ketamine $(90 \mathrm{mg} / \mathrm{kg})$ intraperitonea and rats were sacrificed on day 8. Fallowing that liver tissue samples were obtained and were placed in 10\% neutral formalin.

\section{Histochemical procedure}

Liver tissue samples were washed in water over night then were dehydrated in ethanol (50-60-70-80-90-100\%), were made transparent in xylol and at last were embedded into paraffin. Fallowing that samples were cut with a thickness of 4 $\mu \mathrm{m}$ by microtome (Leica SM2000R, Germany) and were stained by Hematoxylin-Eosin (H-E) than covered with entellan. Histopathological findings were graded and evaluated with photomicroscope by using the semi-quantitative method according to as following.

Structural changes were graded by using the semi-quanitative method. Acording to this;

$$
\begin{aligned}
& (-) \text { (negative score): No structural changes } \\
& (+)(1 \text { positive score): Light structural changes }
\end{aligned}
$$

$(++)(2$ positive score): Middle structural changes

$(+++)$ (3 positive score): Serious structural changes.

\section{Immunohistochemical procedure}

Samples were stained with TNF- $\alpha$ primery ab (rabbit anti-TNF- $\alpha$ antibody, Abcam, Cambridge, USA), iNOS primary ab (rabbit anti-iNOS antibody, Abcam, Cambridge, USA), NF$\mathrm{kB}$ primary ab (rabbit anti- NF-kB antibody, Abcam, Cambridge, USA) and were covered with entellan. Fallowing that, samples receptor densities were graded by the semi-quantitative evaluation method (27).

( - ) (negative score): No staining

$(+)(1$ positive score): Light staining

$(++)(2$ positive score): Middle staining

$(+++)$ (3 positive score): Serious staining

Biochemical Analysis

\section{Blood Biochemical Markers Assay}

The biochemical parameters (Activities of aspartate aminotransferase (AST), alanine aminotransferase (ALT), gamma glutamyl transferase (GGT) and Total Biluribin (T. bilirubin) in serum were measured on an automatic clinical chemistry analyzer (Gesan chem 200, Italy) device in Veterinary Training Hospital of Mehmet Akif Ersoy University.

\section{Measurement of Total Antioxidant Statuus}

Total Antioxidant Status (TAS) kits (Rel Assay Diagnostics kit, Mega Tip, Gaziantep, Turkey) using the spectrophotometric protocol developed by Erel (28) were applied to the tissue homogenates obtained from all experimental groups. Antioxidants in the sample cause the reduction of ABTS (2,2'-azino-bis (3-ethylbenzothiazoline-6-sulphonic acid)) radicals in the kit and cause the disappearance of the dark blue-green color of ABTS. For this purpose, the total antioxidant amount is determined by reading the absorbance of $660 \mathrm{~nm}$ in the spectrophotometer. This analysis is calibrated with Trolox (Vit E analogue), a stable antioxidant solution, and expressed as Trolox equivalent (mmol Trolox Equiv/L).

\section{Measurement of Total Oxidant Status}

The total oxidant status (TOS) of the tissue homogenates obtained from all experimental groups were measured using Rel Assay Kit which spectrophotometric protocol developed by Erel (29). This test is a colorimetric method that is measured spectrophotometrically at $530 \mathrm{~nm}$. Oxidants in the sample oxidize the iron ion chelating complex. Ferric ion forms a chromogenic colored complex in an acidic environment. The intensity of the color is directly proportional to the amount of oxidant in the sample. This assay is calibrated with $\mathrm{H}_{2} \mathrm{O}_{2}$ and the results are shown as $\mathrm{H}_{2} \mathrm{O}_{2}$ equivalent $\left(\mu \mathrm{mol} \mathrm{H}_{2} \mathrm{O}_{2}\right.$ Equi$\mathrm{v} / \mathrm{L})$.

\section{Measurement of Oxidative Stress Index}

The TOS to TAS ratio was regarded as the oxidative stress 
CONTROL

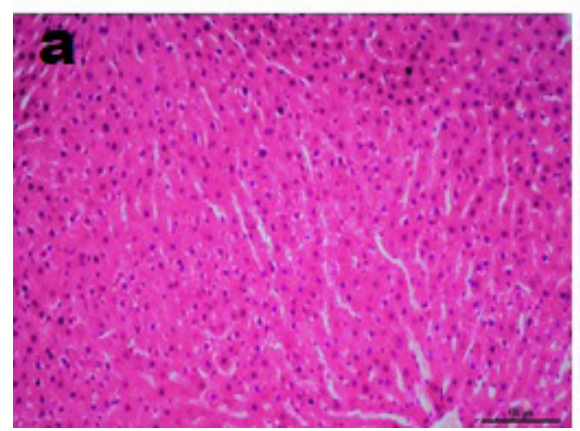

MTX

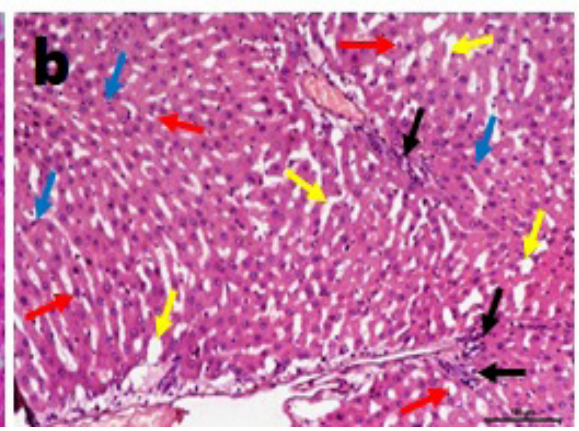

MTX + RSV

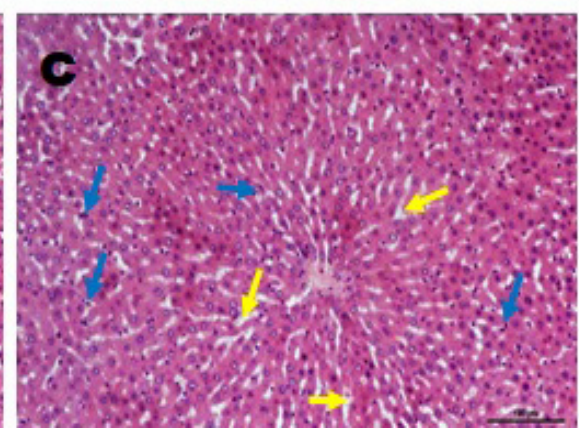

Figure 1. Histopathological findings in liver tissue belonging to control and experimental groups: a, control group, (group I); no histopathological findings were found. b - MTX group (group II), c - MTX + RSV group, (group III). Red arrows; vacuolar - granular degeneration in hepatocytes, blue arrows; picnotic nucleus, black arrows; mononuclear cell infiltration, yellow arrows; sinusodal dilatation, H-E x20.
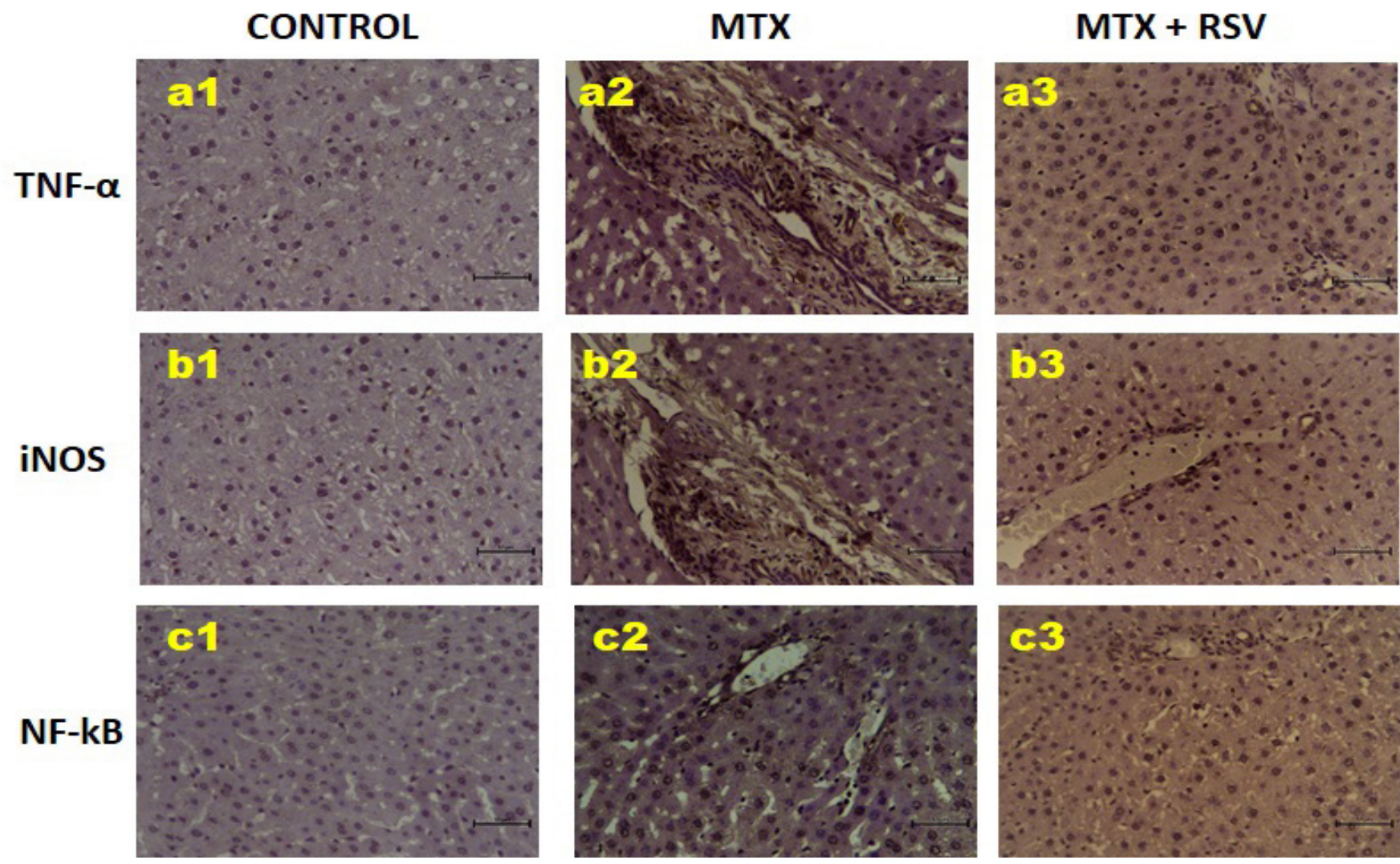

Figure 2. $\mathrm{TNF}-\alpha$, iNOS and NF- $x \mathrm{~B}$ immune stainings in liver tissue in control and experimental groups, respectively. a1-b1-c1, control group, (group I); no positive staining, a2-b2-c2, MTX group, (group II); intensive positive staining, a3-b3-c3, MTX + RSV group, (group III); mild positive stainings, x40.

index (OSI) which is an indicator parameter of the degree of oxidative stress. The OSI value was calculated as follows:

OSI $(\mathrm{AU})=\left[\left(\mathrm{TOS}\right.\right.$, micromoles $\mathrm{H}_{2} \mathrm{O}_{2}$ equivalent per $\left.\mathrm{L}\right) /$ (TAS, micromoles Trolox equivalent per liter)](30).

\section{Statistical Analysis}

Oneway ANOVA (SPSS 18 software) analysis of variance and Dunnett's two-tailed post hoc $t$ test were used for analyzed statistical significance of differences between the all groups. Data were presented as mean + standard error of mean or standard deviation. All findings were considered significant at $\mathrm{p}<0.05$.

\section{RESULTS}

\section{Histochemical Results}

Normal histological structures were observed in the control group (group I), (Fig. 1a). When control groups were compared the Mtx groups (group II) and Mtx+Rsv groups (group III), significantly changes such as; picnotic nucleus, mononuclear cell infiltration, sinusodal dilatation, vacuolar - granular degeneration in hepatocytes were observed in group II and III. But, histological structural changes were lower in group III compared to group II, (Fig. 1b-1c) 
Table 1. Biochemical parameters in the serum

\begin{tabular}{ccccc}
\hline Groups & AST (U/1) & ALT (U/1) & GGT(U/1) & T. Bil.(mg/dl) \\
\hline Control & $116.03 \pm 10.83$ & $24.51 \pm 2.59$ & $8.33 \pm 0.81$ & $0.13 \pm 0.02$ \\
Mtx & $249.23 \pm 11.08^{\mathrm{a}}$ & $73.61 \pm 3.41^{\mathrm{a}}$ & $13.83 \pm 3.43^{\mathrm{a}}$ & $0.52 \pm 0.03^{\mathrm{a}}$ \\
Mtx + Rsv & $126.62 \pm 12.49^{\mathrm{b}}$ & $36.37 \pm 2.16^{\mathrm{a}, \mathrm{b}}$ & $8.75 \pm 0.95^{\mathrm{b}}$ & $0.23 \pm 0.12^{\mathrm{a}, \mathrm{b}}$ \\
\hline
\end{tabular}

Mtx- Methotrexate; Rsv - Resveratrol. Values are presented as means \pm SD. The relationships between groups and results of biochemical markers are assessed by one-way ANOVA. a: $\mathrm{p}<0.05$ vs control, b: $\mathrm{p}<0.05$ vs Mtx.

Table 2. TOS, TAS and OSI markers of liver tissues

\begin{tabular}{|c|c|c|c|c|c|c|}
\hline \multirow[b]{2}{*}{ Groups } & \multicolumn{2}{|c|}{ TOS $(\mu \mathrm{mol} / \mathrm{L})$} & \multicolumn{2}{|c|}{ TAS (mmol/L) } & \multicolumn{2}{|c|}{ OSI (AU) } \\
\hline & Mean \pm SD & $\mathrm{P}$ & Mean \pm SD & $\mathrm{P}$ & Mean \pm SD & $\mathrm{P}$ \\
\hline Control & $23.68 \pm 0.69$ & $* * \mathrm{p}=0.000$ & $1.35 \pm 0.02$ & $* * \mathrm{p}=0.000$ & $1.75 \pm 0.07$ & $*^{*} \mathrm{p}=0.000$ \\
\hline Mtx & $73.40 \pm 1.76$ & $*_{\mathrm{p}}=0.000$ & $1.00 \pm 0.04$ & $*_{\mathrm{p}}=0.000$ & $7.29 \pm 0.36$ & $*_{p}=0.000$ \\
\hline Mtx + Rsv & $27.32 \pm 2.47$ & $\begin{array}{l}*_{\mathrm{p}}=0.019 \\
*^{*} \mathrm{p}=0.000\end{array}$ & $1.24 \pm 0.02$ & $\begin{array}{l}*_{\mathrm{p}}=0.001 \\
* *_{\mathrm{p}}=0.000\end{array}$ & $2.20 \pm 0.24$ & $\begin{array}{l}*_{\mathrm{p}}=0.037 \\
*^{*} \mathrm{p}=0.000\end{array}$ \\
\hline
\end{tabular}

Mtx - Methotrexate; Rsv - Resveratrol. Data are presented as means \pm SD. One way ANOVA (post hoc Tukey test) was used for comparison between groups. ${ }^{*}$ : Comparison with the control group, ${ }^{* *}$ p: Comparison with the Mtx group.

\section{Immnunohistochemical Results}

In 1 mmnunohistochemical results were observed that the TNF- $\alpha$, iNOS and Nf-kB staining were very light in the group I (Fig. 2a1-b1-c1), but were more intense in the group II and group III. When compared group II and group III; staining intensity of the receptors is highest in group II, while less in group III (Fig. 2a2-b2-c2, a3-b3-c3).

In the comparison of $\mathrm{TNF}-\alpha$, iNOS and $\mathrm{NF}-\mathrm{kB}$ receptor staining in all groups, the highest positive staining was found as TNF- $\alpha$, iNOS and NF-kB, respectively.

\section{Biochemical Results}

Changes in serum levels of liver function markers are shown in Table 1. AST, ALT, GGT and Total biluribin levels significantly increased in group II compared to control group $(p<0.05)$, while Rsv admistration significantly decreased all this parameters $(p<0.05)$. TOS, which is an indicator of oxidation products, significantly increased in group II and decreased in group III compared to the control group $(p=0.000$ and 0.019 , respectively). When we compared the group II with the group III, found that the TOS level decreased significantly $(p=0.000)$. TAS, the measure of antioxidant capacity, significantly decreased in group II and group III compared to the control group ( $\mathrm{p}=0.000$ and 0.001 ,respectively). However, TAS level increased significantly in the Rsv+MTX group compared with the MTX group $(\mathrm{p}=0.000)$, (Table 2).

\section{DISCUSSION}

In this study, the possible protective effects of Rsv in Mtx induced hepatotoxicity were investigated. Mtx, is widely used in the treatment of many diseases and has antiinflammatory, immunosuppressive, antiproliferative, antioxidant and cytotoxic effects (1-3). At the same time widely use of Mtx, it has many important side effects, mainly hepatatoxicity (6-8). Studies shows that Mtx leads to oxidative tissue damage via increasing lipid peroxidation in the liver and decreasing the level of antioxidant levels (8, 12-14).

Methotrexate induced mitochondrial damage and following that increased ROS activate. ROS starts lipid peroxidation (LPO) and the release of inflammatory mediators such as TNF- $\alpha, \mathrm{NF}_{-\mathrm{K}} \mathrm{B}$, and iNOS (31). At the end of these cases, proinflammatory cytokines are formed and inflammation increases in important organs such as liver and kidney. $(31,32)$.

Iyer et al reported that expression of $\mathrm{TNF}_{-} \alpha$ incresead in Mtx induced hepatic injury $(31,33)$. The effect of $\mathrm{TNF}-\alpha$, which is important proinflammatory, is mediated by means of 
NF-kB-regulated proteins, such as iNOS and iNOS has a role in the pathogenesis of Mtx induced toxicity $(24,34)$. This study was insvestigated expressions of TNF- $\alpha, \mathrm{NF}-\mathrm{kB}$, and iNOS by immunohistochemically staining and observed that TNF- $\alpha, N F-k B$, and iNOS incresead in Mtx induced hepatotoxicity.

Resveratrol provides antioxidant activities via inhibiting lipid peroxidation, NF-kB, TNF- $\alpha$ and iNOS production and by preventing the inhibition of Glutathione (GSH) levels. Resveratrol has protective effect on oxidative stress by means of several redox associated molecular pathways such as blocking TNF inducing NF-kB-mediated gene transcriptionans (31, 3537). Resveratrol has been widely reported to interfere with NF$\mathrm{kB}$ activity and enhance energy expenditure by increasing lipid oxidation and mitochondrial respiration. Accordingly, Rsv treatment causes large increasing in mitochondrial ingredients in important metabolic tissues like liver and kidney $(17,37)$.

In studies observed that Rsv reduces proinflammatory stimuli, like TNF- $\alpha$, lipopolysaccharide (LPS) and prevents NF$\mathrm{kB}$ translocation due to degradation $(36,38)$. Understanding of the mechanism underlying such actions and how Rsv blocks NF-kB activation by TNF is still unclear. Its suppression of NF-kB activation by a wide various of agents suggests that Rsv must act at a stage common for inflammatory mediators. Many inhibitors of Nf-kB activation, like silymarin and curcumin, mediate their effects by means of degradation of $\mathrm{IkBa}$ and suppression of phosphorylation (36). In fact, evidences for effect of Rsv on NF-kB and TNF are still insufficient. So, this study aimed to investigate the effect of Rsv on Mtx induced hepatotoxicity in rats model by histopathologically, immunohistochemically and biochemically analyses.

Studies reported that Rsv has restorative effect on serum T. Biluribin, GGT, AST and ALT levels in the liver tissues. Similar to present study's results, studies showed that these levels increase in Mtx induced hepatotoxicity, but were significantly decrease in treatment of $\operatorname{Rsv}(1,14)$.

Kawada et al observed that Rsv has inhibiting effect on nitric oxide (NO) and TNF-a via lipopolysaccharide stimulates Kupffer cells $(23,39)$. Additionally, Rsv induced hepatic fibrosis owing to its antioxidative activities and suppressed hepatic stellate cell activation $(35,40)$. Manna et al investigated that effect of Rsv on NF-kB activation induced by various inflammatory mediators and observed that Rsv blocked TNF induced activation of NF-kB (36). Meng et al reported that Rsv protected from inflammation not only by inhibiting the production of inflammatory mediators like TNF- $\alpha$, but also by inducing antiinflammatory heme oxygenase-1 (HO-1) in RAW264.7 macrophages (35). Recently, studies showed that Rsv decreases oxidative damage owing to the induces autophagy via the AMPK by means of prevention of mammalian target of rapamycin (mTOR) pathway or via the activation of transcription factor EB (TFEB) $(35,41)$. Although, many studies of resveratrol's pathways are ongoing, but still different analyses are insufficient for evidence. In present study was observed that TNF- $\alpha, N F-k B$, and iNOS decresead in Rsv treatment groups in Mtx induced hepatotoxicity. Moreover, TOS, TAS and OSI values, oxidant - antioxidant levels and histopat- hological findings supported this results.

Several studies results supports that Rsv reduces lots of chronic diseases and side effects of many drugs such as Mtx. In present study were investigated Rsv role on hepatotoxicity casued by Mtx and were observed that oxidant levels could increase after methotrexate applied in the liver, whereas resveratrol alleviated effects of hepatotoxicity by histopathological, immunohistochemical and biochemical analyses. Althouh stdies about Rsv is still ongoing, understanding of the moleculer mechanism underlying Rsv is still unclear. Performing different analyzes on Rsv pathways, especially in Mtx induced hepatotoxicity, will make the results more reliable. Thanks to the studies conducted in this way, the importance of bioactive componounds will increase and these componounds will be used as the first solution for even in diseases that are very difficult to treat.

\section{DISCUSSION}

The obtained data present the macrometric anatomical parameters of the rabbit adrenal glands. Thus we assume that the results could be used for contemporary investigations in the Human Medicine, because the rabbits are used as animal models (1).

We have conducted the present study in order to obtain objective anatomical data for the macrometric parameter of the rabbit adrenal glands. Our theory deepens the knowledge, because it gives objective information for the variation of LM, CR, CC and DV diameters of the studied organs. This information could be used as model for laboratory experiments to investigate the function of the adrenal gland in humans (2).

Our data will be applicable as anatomical base to study the LM diameter, CR, CC diameter and DV diameter of the rabbit adrenal glands, because this animal species is considered as a pet wand at the same time is predisposed for adrenal glands diseases. Our attitude correspond to the data for the importance of the knowledge for the normal measurements of the glands $(3,4)$.

In our investigation, we used the published data $(5,6)$ for the anatomical peculiarities and topography of the studied organs in the rabbit for better orientation. This study is a continuation of the previous study for the rabbit glands (6) and deepens the knowledge for these glands, because it is focused on the macrometric parameters.

Our algorithm is anatomical and includes the only dissection. We obtained values for the LM diameter of the right and left adrenal glands in sexually mature and clinically healthy animals, separated in two equal groups, regarding the gender. We resume that these anatomical data could be used as a base to study the imaging anatomical specifics of these glands.

Our approach differs from that applied in the cats (7) and dogs (9) to study the adrenal glands, because we include as a method only the dissection. In the same time, we claim that there is a correlation between adrenal gland DV diameter and the values of the body weight. Our theory corresponds to the thesis for this index of the adrenal glands in the $\operatorname{dog}(9)$.

The LM and DV diameters of the rabbit of the right and left adrenal glands were with close values. On the other side 
CR, CC diameter in the both glands are with greater values than LM and DV diameters. The studied parameters of the left gland were with higher values compared to the right gland. According to us, there is a correlation between the values of the adrenal glands' diameters and the values of the body weight. Our attitude corresponds to the theory of some authors (8) for the adrenal glands in the small dog breeds.

\section{CONCLUSION}

The present study was tested that the antioxidant and antiinflammatory effects of Rsv and showed its hepatoprotective effect in Mtx induced hepatotoxicity. Results suggests that the combined effects of bioactive componounds would be beneficial in the protection from Mtx induced hepatotoxicity. In the future, more bioactive componounds and health benefits of Rsv should be investigated, and molecular mechanisms of action need to be studied in more detail. In this sense, our studies continue with different analyzes for clearly understand mechanism of Rsv.

\section{DECLARATIONS}

\section{Ethics Approval}

Permission for the use of animals in this study was given by the This study was approved by animal ethics committee of Mehmet akif Ersoy University (MAKÜ, Ethical number: 17.03.2021$87 / 742$ ) and was performed entirely according to ethical rules.

\section{Conflict of Interest}

All authors declare that they have no conflict of interest.

\section{Author Contribution}

M Özgöçmen: Investigation, Histological analysis, Data curation, Validation, Visualization, Writing - original draft.

Ş Yeşilot: Funding acquisition, Project administration, Investigation, Methodology, Biochemical analysis.

\section{Data Availability}

The data that support the findings of this study are available from the corresponding author upon reasonable request.

\section{REFERENCES}

1. Tunali-Akbay T, Sehirli O, Ercan F, Sener G. Resveratrol protects against methotrexate-induced hepatic injury in rats. Journal of pharmacy \& pharmaceutical sciences : a publication of the Canadian Society for Pharmaceutical Sciences, Societe canadienne des sciences pharmaceutiques. 2010;13(2):303-10.

2. Sharma S, Baboota S, Amin S, Mir SR. Ameliorative effect of a standardized polyherbal combination in methotrexate-induced nephrotoxicity in the rat. Pharmaceutical biology. 2020;58(1):184-99.

3. Ebrahimi R, Sepand MR, Seyednejad SA, Omidi A, Akbariani M, Gholami M, et al. Ellagic acid reduces methotrexate-induced apoptosis and mitochondrial dysfunction via up-regulating Nrf2 expression and inhibiting the $I_{k} B \alpha / N_{K} B$ in rats. Daru : journal of Faculty of Pharmacy, Tehran University of Medical Sciences. 2019;27(2):721-33.

4. Hasan H, Ismail H, El-Orfali Y, Khawaja G. Therapeutic benefits of Indole-3-Carbinol in adjuvant-induced arthritis and its protective effect against methotrexate induced-hepatic toxicity. BMC Complement Altern Med. 2018;18(1):337.

5. Taskin B, Erdoğan MA, Yiğittürk G, Günenç D, Erbaş O. Antifibrotic Effect of Lactulose on a Methotrexate-Induced Liver Injury Model. Gastroenterology research and practice. 2017;2017:7942531.

6. Genestier L, Paillot R, Quemeneur L, Izeradjene K, Revillard J-P. Mechanisms of action of methotrexate. Immunopharmacology. 2000;47(2-3):247-57.

7. Samdanci ET, Huz M, Ozhan O, Tanbek K, Pamukcu E, Akatli AN, et al. Cytoprotective effects of molsidomine against methotrexate-induced hepatotoxicity: an experimental rat study. Drug design, development and therapy. 2019;13:13-21.

8. Vardi N, Parlakpinar H, Cetin A, Erdogan A, Cetin Ozturk I. Protective effect of $\beta$-carotene on methotrexate-induced oxidative liver damage. Toxicologic pathology. 2010;38(4):5927.

9. Cao Y, Shi H, Sun Z, Wu J, Xia Y, Wang Y, et al. Protective Effects of Magnesium Glycyrrhizinate on Methotrexate-Induced Hepatotoxicity and Intestinal Toxicity May Be by Reducing COX-2. Frontiers in pharmacology. 2019;10:119.

10. Amirfakhrian H, Abedi SM, Sadeghi H, Azizi S, Hosseinimehr SJ. The use of $99 \mathrm{~m}$ Tc-phytate for assessment the protective effect of vitamin $\mathrm{E}$ against hepatotoxicity induced by methotrexat in rat. Nuclear medicine review Central \& Eastern Europe. 2018;21(1):8-13.

11. Vittori Gouveia LdA, Cardoso CA, de Oliveira GMM, Rosa G, Moreira ASB. Effects of the intake of sesame seeds (Sesamum indicum L.) and derivatives on oxidative stress: A systematic review. Journal of medicinal food. 2016;19(4):33745.

12. Moghadam AR, Tutunchi S, Namvaran-Abbas-Abad A, Yazdi M, Bonyadi F, Mohajeri D, et al. Pre-administration of turmeric prevents methotrexate-induced liver toxicity and oxidative stress. BMC complementary and alternative medicine. 2015;15(1):1-13.

13. Neradil J, Pavlasova G, Veselska R. New mechanisms for an old drug; DHFR-and non-DHFR-mediated effects of methotrexate in cancer cells. Klin Onkol. 2012;25(Suppl 2):2S872S92.

14. Al Kury LT, Dayyan F, Ali Shah F, Malik Z, Khalil AAK, Alattar A, et al. Ginkgo biloba Extract Protects against Methotrexate-Induced Hepatotoxicity: A Computational and Pharmacological Approach. Molecules. 2020;25(11).

15. Burns J, Yokota T, Ashihara H, Lean ME, Crozier A. Plant foods and herbal sources of resveratrol. Journal of agricultural and food chemistry. 2002;50(11):3337-40.

16. Li S, Zheng X, Zhang X, Yu H, Han B, Lv Y, et al. Exploring the liver fibrosis induced by deltamethrin exposure in quails and elucidating the protective mechanism of resveratrol. Ecotoxicol Environ Saf. 2021;207:111501. 
17. Kulkarni SS, Cantó C. The molecular targets of resveratrol. Biochimica et biophysica acta. 2015;1852(6):1114-23.

18. Dilek OG, Dimitrov RS, Stamatova-Yovcheva KD, Yovchev DG, Mihaylov R. Importance for experiments in human medicine of imaging modalities for macroanatomical and histological study of rabbit suprarenal glands. Medycyna Weterynaryjna. 2019;75(11).

19. Dilek OG, Erden H. Age, Sex and Body Weight Related Echocardiographic Parameters of Clinically Healthy New Zealand White Rabbits. Acta Scientiae Veterinariae. 2019;47(1).

20. Dilek ÖG, Erden H, Turan E, Dimitrov R, Stamatova-Yovcheva K, Karakurum E. The qualitative and quantitative assessment of the renal cortex of the clinically healthy rabbits. Ankara Üniversitesi Veteriner Fakültesi Dergisi. 2020;67(4):381-6.

21. Haligür A, Karakurum E, Dilek ÖG. Morphological aspects of the pancreas in the rat and the rabbit: An investigation into the location, ducts, arteries and veins. Mehmet Akif Ersoy Üniversitesi Veteriner Fakültesi Dergisi. 2018;3(2):96-101.

22. Mattison JA, Wang M, Bernier M, Zhang J, Park S-S, Maudsley S, et al. Resveratrol prevents high fat/sucrose diet-induced central arterial wall inflammation and stiffening in nonhuman primates. Cell metabolism. 2014;20(1):183-90.

23. Fremont L. Biological effects of resveratrol. Life sciences. 2000;66(8):663-73.

24. Eki Nci-Akdemi RF, Yildirim S, Kandemi RF, Gülçi Ni, Küçükler S, Sağlam YS, et al. The effects of casticin and myricetin on liver damage induced by methotrexate in rats. Iranian journal of basic medical sciences. 2018;21(12):1281-8.

25. Kocaman N, Çolakoğlu N. Tekrarlayan Dozlarda Metotreksat Uygulamasının Siçan Böbrek Dokusu Üzerine Etkileri. Firat Tip Dergisi. 2013;18(4):198-202.

26. Yuluğ E, Türedi S, Alver A, Türedi S, Kahraman C. Effects of resveratrol on methotrexate-induced testicular damage in rats. The scientific world journal. 2013;2013: 489659. DOI: 10.1155/2013/489659. eCollection 2013.

27. Refaiy A, Muhammad E, ElGanainy E. Semiquantitative smoothelin expression in detection of muscle invasion in transurethral resection and cystectomy specimens in cases of urinary bladder carcinoma. African Journal of Urology. 2011;17(1).

28. Erel O. A novel automated direct measurement method for total antioxidant capacity using a new generation, more stable ABTS radical cation. Clinical biochemistry. 2004;37(4):277-85.

29. Erel O. A new automated colorimetric method for measuring total oxidant status. Clinical biochemistry. 2005;3 (12):1103-11.

30. Kosecik M, Erel O, Sevinc E, Selek S. Increased oxidative stress in children exposed to passive smoking. International journal of cardiology. 2005;100(1):61-4.
31. Mahmoud AM, Hussein OE, Hozayen WG, Abd elTwab SM. Methotrexate hepatotoxicity is associated with oxidative stress, and down-regulation of PPAR $\gamma$ and Nrf2: Protective effect of $18 \beta-$ Glycyrrhetinic acid. Chemico-biological interactions. 2017;270:59-72.

32. Liedtke C, Trautwein C. The role of TNF and Fas dependent signaling in animal models of inflammatory liver injury and liver cancer. European journal of cell biology. 2012;91(6-7):582-9.

33. Iyer VV, Ovacik MA, Androulakis IP, Roth CM, Ierapetritou MG. Transcriptional and metabolic flux profiling of triadimefon effects on cultured hepatocytes. Toxicology and applied pharmacology. 2010;248(3):165-77.

34. Elsawy H, Algefare AI, Alfwuaires M, Khalil M, Elmenshawy OM, Sedky A, et al. Naringin alleviates methotrexate-induced liver injury in male albino rats and enhances its antitumor efficacy in HepG2 cells. Bioscience reports. 2020;40(6).

35. Meng X, Zhou J, Zhao CN, Gan RY, Li HB. Health Benefits and Molecular Mechanisms of Resveratrol: A Narrative Review. Foods (Basel, Switzerland). 2020;9(3).

36. Manna SK, Mukhopadhyay A, Aggarwal BB. Resveratrol suppresses TNF-induced activation of nuclear transcription factors NF- $x \mathrm{~B}$, activator protein-1, and apoptosis: potential role of reactive oxygen intermediates and lipid peroxidation. The Journal of Immunology. 2000;164(12):6509-19.

37. Tsai SH, Lin $\square$ Shiau SY, Lin JK. Suppression of nitric oxide synthase and the down $\square$ regulation of the activation of $\mathrm{NF} \varkappa \mathrm{B}$ in macrophages by resveratrol. British journal of pharmacology. 1999;126(3):673-80.

38. Mammadov R, Suleyman B, Akturan S, Cimen FK, Kurt $\mathrm{N}$, Suleyman Z, et al. Effect of lutein on methotrexate-induced oxidative lung damage in rats: a biochemical and histopathological assessment. The Korean journal of internal medicine. 2019;34(6):1279.

39. Kawada N, Seki S, Inoue M, Kuroki T. Effect of antioxidants, resveratrol, quercetin, and $\mathrm{N} \square$ acetylcysteine, on the functions of cultured rat hepatic stellate cells and Kupffer cells. Hepatology. 1998;27(5):1265-74.

40. Ahmad A, Ahmad R. Resveratrol mitigate structural changes and hepatic stellate cell activation in N'-nitrosodimethylamine-induced liver fibrosis via restraining oxidative damage. Chemico-biological interactions. 2014;221:1-12.

41. Zhou X, Yang J, Zhou M, Zhang Y, Liu Y, Hou P, et al. Resveratrol attenuates endothelial oxidative injury by inducing autophagy via the activation of transcription factor EB. Nutrition \& metabolism. 2019;16(1):1-12. 